Revista lus et Praxis, Año 17, No 1, 2011, pp. 31 - 56

ISSN 0717 - 2877

Universidad de Talca - Facultad de Ciencias Jurídicas y Sociales

"Evolución y actualidad de la concepción de familia. Una apreciación de la incidencia positiva de las tendencias dominantes a partir de la Reforma del Derecho Matrimonial chileno"

Jorge del Picó Rubio

\title{
EVOLUCIÓN Y ACTUALIDAD DE LA CONCEPCIÓN DE FAMILIA. UNA APRECIACIÓN DE LA INCIDENCIA POSITIVA DE LAS TENDENCIAS DOMINANTES A PARTIR DE LA REFORMA DEL DERECHO MATRIMONIAL CHILENO*
}

\author{
THE EVOLUTION AND UPDATE OF THE FAMILY CONCEPT, AN APPROACH TO \\ THE POSITIVE EFFECT OF THE PREDOMINANT TENDENCIES, FROM THE CHILEAN \\ MARRIAGE LAW REFORM
}

Jorge Del Picó RuBio**

\begin{abstract}
RESUMEN
Las reformas específicas introducidas al Derecho de familia en las últimas décadas, tanto en Chile como en la experiencia comparada, han tenido como marco de referencia ineludible una compleja y dinámica discusión sobre el concepto de familia que, delimitado normativamente, ha sido recogido en el Derecho positivo.

El trabajo, a partir de las particulares circunstancias del proceso de reforma al Derecho matrimonial chileno, iniciado en 1991 y concluido en 2004, ofrece una revisión de la concepción de familia tenida en vista con ocasión de la discusión desarrollada en dicha oportunidad, tanto en sede legislativa como doctrinaria, abordando los problemas de la delimitación conceptual, las opciones disponibles y su fundamentación ideológica, una visión contemporánea de sus funciones, la evolución apreciada de las concepciones sociales dominantes y su incidencia positiva, para concluir con una aproximación crítica a la familia en su expresión nuclear. Sobre el análisis precedente, constata la agudización del proceso de debilitamiento del modelo tradicional de ordenación familiar, propone un enfoque particular de las causas de la crisis de la familia, advierte las consecuencias jurídicas y sociales del predominio acusado de la autonomía individual en este campo y procura instalar las bases para discutir una revalorización de la familia en perspectiva social y comunitaria, en su expresión natural.
\end{abstract}

ABSTRACT

The specific modifications made the past decades to the Family Law, as well in Chile as in the compared experience, have had as an unavoidable frame of reference a complex and dynamic discussion about the legally restrained family concept, which has been collected in the positive Law.

\footnotetext{
* Trabajo recibido el 30 de agosto de 2010 y aprobado el 5 de enero de 2011.

${ }^{* *}$ Doctor en Derecho de la Universidad de Zaragoza; Profesor de Derecho Civil y Ciencias del Derecho en la Facultad de Ciencias Jurídicas y Sociales de la Universidad de Talca (Chile). Correo electrónico: jlp@utalca.cl.
} 
This work, from the particular circumstances of the Chilean Marriage Law reform process, started in 1991 and finished in 2004, offers a revision of the family conception taken into consideration during the discussion developed in that opportunity, informing the conceptual limits problems, the available options and ideological founding, a contemporary vision of its functions, the dominant social concepts evolution and their positive effect, concluding with a critic approach to the family in its nuclear expression.

Regarding the previous analysis, it is stated the sharpness weaken process of the traditional family model, proposed a particular approach of the family crisis causes, warned the juridical and social consequences of the predominance accused on this field of the individual autonomy, and tries to establish the basis to discuss the family reassessment in the social and community perspective, on its natural expression.

PALABRAS CLAVE

Familia y Derecho, Concepto de Familia, Derecho Matrimonial

KEY WORDS

Law and Family, Family Concept, Marriage Law

\section{El CONCEPTO de familia y los problemas de Su Delimitación}

La dificultad para establecer un concepto de familia que suscite aceptación general o mayoritaria, es ya una referencia común en la doctrina de las ciencias sociales y, particularmente, en las ciencias jurídicas. De igual modo, una pretensión de alcance más reducido, como establecer una concordancia en sus bases mínimas o en la selección de los criterios necesarios para la construcción conceptual, también parece lejana, reconociendo esta dificultad su origen en la radicación de la noción de familia en distintas esferas disciplinarias, allende el Derecho.

Como acertadamente constata Estrada ${ }^{1}$, su causa fundamental la brinda la relatividad y temporalidad del concepto, es decir, la necesidad de aceptar la concurrencia de distintas visiones sociológicas, teológicas y filosóficas conjuntamente con su necesaria apreciación histórica. Asimismo, la actual realidad, muchas veces crítica de las situaciones de convivencia, ha contribuido con lo suyo a la ampliación de la búsqueda de las causas de los problemas paterno filiales y de convivencia conyugal en la propia definición de familia y su íntima ligazón histórica con el matrimonio, antes aceptada como dato necesario de su comprensión y hoy como causa de sus problemas².

\footnotetext{
${ }^{1}$ Cfr. Estrada Alonso, Eduardo, Las uniones extramatrimoniales en el Derecho civil español, Civitas, Madrid, 1986, p. 93.

2 Para una apreciación de la visión crítica sobre la noción tradicional de familia, vide también MALUQUER De Motes, Carlos, Derecho de familia, Bosch, Barcelona, 2005, pp. 19-20. Los aspectos históricos, etimológicos y una acertada visión de conjunto sobre la familia en la doctrina chilena, se encuentran apropiadamente tratados en Corral TalCIANI, Hernán, Familia y Derecho, Universidad de los Andes, Santiago de Chile, 1994, pp. 1 y ss.
} 
EVOLUCIÓN Y ACTUALIDAD DE LA CONCEPCIÓN DE FAMILIA. UNA APRECIACIÓN DE LA INCIDENCIA POSITIVA DE LAS tendencias dominantes a partir de la Reforma del Derecho Matrimonial chileno

El propósito de esta somera visita a la noción de familia, asumiendo la dificultad precedentemente señalada y la superabundancia de opiniones y de información disponible sobre la materia, se limita a exponer algunas concepciones y perspectivas que incidieron en la modelación del nuevo Derecho matrimonial chileno, considerando tanto el impacto del debate previo en la doctrina de referencia y la discusión simultánea a la tramitación de la NLMC acaecido en Chile, así como algunas referencias comparadas que revistan interés por su efectiva influencia en dicho proceso, con el propósito de adelantar una primera lectura reflexiva sobre el acuerdo tácito y el progresivo asentamiento de una nueva concepción pública de familia ${ }^{3}$.

Al enfocar doctrinariamente el término familia, se aprecia tempranamente la ausencia de coincidencia en cuanto a su significado, motivada por la incontrarrestable influencia de criterios restrictivamente disciplinarios ${ }^{4} \mathrm{O}$ derechamente de naturaleza ideológica ${ }^{5}$, que determinan su construcción conceptual y terminológica. Así, por ejemplo, en la perspectiva jurídica, la familia es asumida como una institución jurídica, vale decir, un complejo de relaciones regidas por normas jurídicas. Sociológicamente, en cambio, se aprecia esencialmente una realidad social, respecto de la cual el Derecho o está ajeno o es accesorio ${ }^{6}$.

Asumiendo lo expuesto precedentemente, cabe señalar la coincidencia de perspectivas distintas en el objeto de estudio, factor que puede ser traducido en la apreciación de la familia como grupo social y también como institución social.

\footnotetext{
${ }^{3}$ Una tipología de la familia, que incluye, basado en la doctrina española, las recurrentes nociones de familia nuclear en todas sus acepciones y los criterios de legitimidad familiar derivados de la valorización tradicional del matrimonio, puede ser apreciada en CORRAL, Familia, cit. nota n. 2, pp. 12-15; para una reseña histórica de las raíces de la vida en familia, vide TrimBos, Carlos, Convivencia en el matrimonio y la familia, Carlos Lohlé, Buenos Aires, 1966, pp. 15 y ss.; una perspectiva de interés en la doctrina civil americana, puede ser apreciada en CoRnejo CHÁvez, Héctor, Derecho familiar peruano, $10^{a}$ Edición, Gaceta Jurídica, Lima, 1999, pp. 13-42, y en MizraHı, Mauricio, Familia, matrimonio y divorcio, Astrea, Buenos Aires, 2001, pp. 1-152. Para una visión sintética, de carácter sociológico, sobre la situación de la familia en distintas sociedades contemporáneas, vide CASTELLÁN, Ivonne, La familia, Traducción de Martínez, H., Fondo de Cultura Económica, México, 1995, pp. 13-64.

${ }^{4}$ Siguiendo a Marqueño de Llano, la familia es el presupuesto sociológico del Derecho de familia, permitiendo afirmar coherentemente que las modificaciones de las normas jurídicas vienen propiciadas o exigidas por la necesidad de atender a las distintas metamorfosis que a lo largo de los últimos años ha experimentado el concepto de familia (MARQueño de Llano, en NAVArRo Viñuales, José María (Dir.), El nuevo Derecho de familia: modificaciones legislativas y tendencias doctrinales, Thomson Civitas, Cizur Menor, Navarra, 2006, p. 9).

${ }^{5} \mathrm{~A}$ modo ejemplar, considérese la pretensión en tal sentido de los liberales promotores de la teoría del Análisis económico del Derecho, como antaño pretendieron los neomarxistas. Una interesante muestra del debate en esta perspectiva, puede ser apreciada en PÉREz ADÁN, José, Repensar la familia, Ediciones Internacionales Universitarias, 2005, pp. 75-81, notas marginales.
}

${ }^{6}$ Cfr. Diez-Picazo, Luis, Familia y Derecho, Civitas, Madrid 1984, p. 21. 
Así, en tanto grupo social, la familia destaca como un complejo sistema de relaciones personales, constituido por las relaciones de filiación, las relaciones conyugales y las relaciones de fraternidad. Considerando en primer lugar las relaciones de filiación, se alude a un grupo social formado por los miembros que integran el hogar, emparentados entre sí por lazos de sangre, adopción o matrimonio, incluyéndose las uniones consensuales cuando son estables, es decir, basadas en la progenie común. Esta perspectiva admite la consideración de la filiación como eje de la familia, sin perjuicio de la estrecha conexión entre filiación y matrimonio. Respecto de éste, se asume su relación con la familia, pero no su identidad, ya que mientras el matrimonio considera la vinculación entre dos adultos de distinto sexo, la familia y, particularmente, la filiación, comprende la relación entre generaciones diferentes, como ocurre en el caso de padres e hijos. A partir de la complejidad indicada, la familia debe ser considerada como un concepto más amplio, inclusivo por tanto del matrimonio y la filiación 7 .

En la segunda apreciación, en tanto institución social, se incluye el conjunto de valores y normas compartidas, que orientan el modo de pensar, sentir y actuar de las personas que constituyen las familias, influyendo en la forma de integración y en el reconocimiento de derechos y deberes al interior del colectivo familiar. Esta perspectiva comprende las normas jurídicas y las normas de trato social que la rigen, regulando los actos vinculados a los momentos determinantes de la vida familiar, tales como la elección de pareja, el matrimonio,

\footnotetext{
${ }^{7}$ La heterogeneidad de perspectivas en torno a la familia discurren desde la apreciación de su peculiaridad como grupo humano (Díez-Picazo, Luis; Gullón Ballesteros, Alberto, Sistema de Derecho civil, IV, $10^{a}$ Edición, Tecnos, Madrid 2006, p. 33), como grupo social (LASARTE, Carlos, Derecho de familia, $4^{a}$ Edición, Marcial Pons, Madrid, 2005, pp. 5-7), hasta la mayoritaria consideración de la relevancia de la consanguinidad o parentesco de sangre, ligada total o preferentemente al matrimonio (VILADRICH, Pedro Juan, La familia. Documento 40 ONG's, Rialp, Madrid 1994, pp. 27 y 28, e IDEM, "La familia soberana", «IC» 68 (1994) pp. 427-440; Castán TobeÑas; B. Pérez González, en T. Kipp, Theodor; WolfF, Martín, Derecho de Familia, I, Bosch, Barcelona, 1947, pp. 7-10; González PorRAS, José Manuel, La familia, el derecho y la libertad, Monte de Piedad, Córdoba 1987, pp. 16 y ss.) o, derechamente, una comunidad creada por el matrimonio y compuesta principalmente por progenitores y procreados (Lacruz Berdejo, José Luis, Elementos de Derecho civil, IV, familia, Dykinson, Madrid 2002, pp. 1-3). Finalmente, es interesante considerar la perspectiva de Castán Tobeñas, quien asumiendo la naturaleza factual de la familia, considera a la familia como "una realidad ético-social que no se basa en la voluntad" (Cfr. CAstán Tobeñas, Derecho civil español, común y foral, V, Derecho de familia, $12^{a}$ Edición, vol. I, Reus, Madrid, 1994, p. 43).

En lo que respecta a la provisión de datos y la construcción de un concepto sobre antecedentes sociológicos en Chile, confróntese ReYEs, Carmen, "La Familia chilena hoy. Fundamentos para políticas públicas orientadas al grupo familiar", en Ayımin Orarzún, Mariana y Otros, La familia en Chile: Aspiraciones, realidades y desafíos, CERC/ICHEH, Santiago de Chile 1992, p. 38. Asimismo, para una apreciación sociológica de las transformaciones apreciadas en la familia americana, vide ARRIAGADA, Irma, "Transformaciones sociales y demográficas de las familias latinoamericanas", en VALDÉs, Ximena; VAlDÉs, Teresa (Edits.), Familia y vida privada. ¿Transformaciones, tensiones, resistencias y nuevos sentidos?, FLACSO, Santiago de Chile 2005.
} 
la concepción, el cuidado, la educación y socialización de los hijos, los roles conyugales y el cuidado de los integrantes dependientes, como los adultos mayores. También está presente aquí una visión que se erige sobre la noción de autoridad familiar, considerando al grupo a partir de sus vínculos de parentesco o de su calidad de cónyuges, y en la cual éstos aseguran en conjunto su dirección moral y material. En esta perspectiva, cada sociedad desarrolla su propia noción de la institución familiar, protegiéndola o promoviéndola mediante su tutela jurídica privilegiada ${ }^{8}$.

La necesaria distinción disciplinaria ha considerado la variedad semántica constituida en torno al concepto de familia, toda vez que la atribución de un determinado significado es siempre compleja, pues depende del punto de vista o interés particular de quien observa el objeto, a quien exige el uso de un lenguaje apropiado para expresar lo que se "entiende" por algo -en este caso la familia- en un determinando momento y contexto histórico y cultural. Así, si el interés manifiesto es regular jurídicamente la familia, corresponde al Derecho observar la familia y definirla, reflejando dicho punto de vista en la norma. En cambio, si la mirada proviene de otras disciplinas, corresponderá a las respectivas categorías de análisis disciplinarias, a su bagaje conceptual y a su lenguaje establecer la definición, que reconocerá ese origen. Así, por ejemplo, en una perspectiva sociológica de base estadística, la forma en que es medida la familia, depende de las clasificaciones que la ciencia estadística elabora para proceder a su medición, como tipologías y modelos de análisis. En cambio, si se opta por intentar comprender la familia desde el punto de vista psicológico, lo relevante serán las vivencias, las fantasías, las percepciones interiores, los sentimientos y, en general, las dinámicas psíquicas de los sujetos implicados ${ }^{9}$.

El proceso de delimitación de los elementos incluidos en el concepto, propio del trabajo que implica una definición de familia, lo mismo que su traducción positiva, ha enfrentado dificultades evidentes, por causas similares a las indicadas respecto de la propia elaboración conceptual. Así, los intentos de definición

\footnotetext{
${ }^{8}$ Cfr. Mazeaud, Henri y Otros, en Corral, Familia, cit. nota n. 2, p. 6. El mismo sentido es destacado en Trimbos, Carlos, Convivencia, cit. nota n. 3, p. 52. Díez-Picazo y Gullón, por su parte, concluyen que la noción de familia, puede confrontarse jurídicamente con la noción de comunidad doméstica (DíEzPICAZO; Gullón, Sistema, cit. nota n. 7, p. 31). Maluquer de Motes, en consonancia con la perspectiva descrita, considera que la familia constituye una organización de grupos sociales, que conlleva unas determinadas formas de comportamiento, de creencias, de tradiciones y de necesidades económicas, siendo el lugar en el cual se realiza y desarrolla la persona (Cfr. MaLUQUeR, El Derecho, cit. nota n. 2, p. 22). Finalmente, la función familiar de articulación entre la persona singular y la sociedad general es destacada en VILADRICH, La familia, cit. nota n. 7, p. 20.

${ }^{9}$ Cfr. Hantrais-Letabler, citado por Donati, Pierpaolo, Manual de Sociología de la familia, Traducción de Herrera, M.; Pagés, S., Pamplona, 2003, p. 20-21.
} 
han adoptado como criterios rectores el fundamento del parentesco común ${ }^{10}$, de la radicación física ${ }^{11}$ o de su funcionalidad ${ }^{12}$, por citar algunos.

Jurídicamente, el Derecho chileno no ha contemplado una definición o concepto de familia públicamente utilizado en documentos oficiales, salvo la remota y limitada referencia contenida en el artículo 815 del Código Civil, con ocasión de la regulación de los derechos de uso y habitación.

Un primer intento de aproximación a una norma declarativa en el ámbito del Derecho de familia, se puede establecer en el marco del estudio tendiente a configurar las bases de una futura política nacional sobre la familia, a partir de un diagnóstico compartido sobre su realidad, a principios de la década de 1990 y que confluyó en el Informe emitido en 1993 por la Comisión Nacional de la Familia, constituida durante el gobierno del Presidente Aylwin. El citado informe contendría una definición de familia, que luego retomaría el Ministro de Justicia, Luis Bates al fundamentar las indicaciones al proyecto de NLMC aprobado por la Cámara de Diputados, en 2002. La definición aludía a, "un grupo humano y social, constituido por la unión de un hombre y una mujer, con voluntad de permanencia o estabilidad en el tiempo, constituido por la unión de un hombre y una mujer con aptitud legal para comprometerse a compartir la vida y, sobre esta base, crear un hogar, con o sin hijos propios o adoptivos"13.

Su importancia posterior radica en su carácter de fuente para acceder a las tendencias influyentes en el debate parlamentario de este cuerpo legal,

\footnotetext{
${ }^{10}$ Enfocan la familia como un grupo de personas que comparten una relación de parentesco, conyugalidad, filiación o fraternidad. Admiten la distinción entre lazos parentales de sangre, adoptivos o de alianza. Así, Kıpp; Wolf, Derecho, cit. nota n. 7, p. 2, y CASTÁN, Derecho, cit. nota n. 7, p. 39.

${ }^{11}$ Consideran la familia como un grupo de personas emparentadas o no, que conviven en un mismo hogar sometidos a la dirección y recursos del jefe de la casa, expresándose en lo que se conoce como la familia residencia. Esta acepción, presente en el Derecho español tradicional desde las antiguas leyes de Partida, coincide con la recogida en la limitada definición del CCCH, muy común en el siglo XIX, que además de las funciones económicas tenía en especial resguardo la asignación de poder de una unidad económica que se proyectaba políticamente. Cfr. CASTÁn, Derecho, cit. nota n. 7, pp. 38 y 39.

${ }^{12}$ Cfr. Pérez, José, Repensar, cit. nota n. 5, p. 80.

${ }^{13}$ Vide Diario Oficial, Antecedentes y Texto Ley Nº 19.947, p. 58, y el Mensaje de presentación de las indicaciones al proyecto de ley que modifica la ley que establece nueva Ley de matrimonio civil, en Senado de la República de Chile, Boletín № 1759-18, de 13 de septiembre de 2001, p. 5. Coincidentemente, esta misma noción de familia, con sus mismas características estructurantes, también se ha podido apreciar en el producto de un trabajo colectivo de reflexión sobre la familia, efectuado en España a principios de la presente década, cuyos elementos principales coinciden con la definición de la CNF, al describir la familia como "toda unión de un hombre y una mujer con vocación de estabilidad en el tiempo, que comparten una vivienda y una economía común, así como los ascendientes y descendientes comunes, unidos ya sea por lazos consanguíneos o de alianza y con los que no necesariamente tienen que mantener ni vivienda ni economía común". Vide el Informe España 2002, una interpretación de su realidad social, elaborado por la Fundación Futuro y citado en FLECHA ANDRÉs, Juan, La transmisión de valores en la familia multicultural, Madrid, 2002, p. 217.
} 
permitiendo contextualizar el producto normativo posterior con una mayor rigurosidad interpretativa ${ }^{14}$.

Finalmente, en una conclusión sintética a partir de las aproximaciones ya realizadas, podemos afirmar que la familia como realidad y como objeto de estudio, es un fenómeno universal, presente en cualquier tipo de sociedad, distinguiendo en sus elementos comunes la unión duradera de un varón, una mujer y sus hijos. Tanto su definición esencial como su justificación social, se basan ineludiblemente en la familia natural, entendida de un modo integral, como un grupo primario de carácter comunitario, constituido materialmente por la residencia común, las relaciones de cooperación y la reproducción, y subjetivamente, por lazos afectivos basados en la sangre y en la alianza, mediante el cual la sociedad realiza algunas funciones esenciales para su supervivencia y, superado este estadio primario de evolución, se erige también como la entidad que realiza aquellas funciones sociales que no pueden ser realizadas por instituciones distintas de la familia, vale decir, el lugar en que se constituyen las relaciones fundamentales decisivas de la persona. En tal perspectiva, no es posible que una sociedad determinada produzca los bienes, códigos y símbolos que requiere para operar, sin su concurso como referente empírico y ético significativo ${ }^{15}$.

\section{NueVA REVISIÓN DE LAS FUNCIONES DE LA FAMILIA}

La familia, al margen de las visiones disciplinarias que se tengan de ella, cumple diversas funciones sociales, cuya valoración pública determina la tutela jurídica expresada en el Derecho de familia. Enfocaremos aquellas que la doctrina ha estimado principales, esbozando una mirada crítica sobre los facilitadores y obstaculizadores que inciden en su logro en la actualidad.

En la visión tradicional, muy arraigada en la enseñanza histórica del Derecho de familia, se han distinguido las funciones afectiva, procreadora, cultural,

${ }^{14}$ Cfr., Diario Oficial, Antecedentes y Texto, cit. nota n. 13, p. 58. Para una perspectiva crítica de dicha definición, vide Declaración del Comité Permanente del Episcopado de la Iglesia Católica chilena, de 6 de noviembre de 2001. Asimismo, Deı Pıcó Rubıo, Jorge, Derecho matrimonial chileno, AbeledoPerrot, Santiago de Chile, 2010, p. 43

${ }^{15}$ Cfr. Hernández-Sampelayo, María; Crespo Garrido, Marcelo, ¿Familia o familias? Estructura familiar en la sociedad actual, Sekotia, Madrid 2005, pp. 20 y ss. Las autoras, en una interesante mirada interdisciplinaria conjuntamente realizada con Pérez-Tomé Román, recurren a los estudios en profundidad sobre el origen y la estructura familiar desarrollados por Levy-Strauss y Murdock, permitiéndoles concluir en la afirmación que "la familia entendida como una comunidad de padres, hijos y otros miembros organizados en torno al matrimonio monogámico y heterosexual, es un fenómeno generalizado de forma universal sobre el que se constituye el desarrollo histórico de la sociedad". Asimismo, considérese Buttiglione, Rocco, La persona y la familia, Traducción de Esquivias, A., Palabra, Madrid 1999, p. 119. 
económica y política, adquiriendo preeminencia las dos primeras, pues aseguran la existencia de la familia' ${ }^{16}$.

Sin embargo, al aplicar una visión más contemporánea, las funciones atribuidas a la familia adquieren mayor complejidad al ser analizadas multidisciplinariamente ${ }^{17}$.

Así, se pueden distinguir otras funciones, partiendo por distinguir en primer lugar una función de equidad generacional, caracterizada por la promoción de la solidaridad diacrónica, entendida como la corresponsabilidad intergeneracional entre ascendientes y descendientes. En segundo lugar, la función de transmisión cultural, pues se considera que la familia natural educa en la lengua, las costumbres, las creencias religiosas, las formas de relación legitimadas socialmente y el trabajo. En tercer lugar, la función de socialización, que alude a la provisión de los conocimientos, habilidades, virtudes y relaciones que permiten a una persona la pertenencia a un grupo social más amplio, pues se tiende a coincidir en su apreciación como una comunidad, inserta en una red de comunidades. En cuarto lugar, cumple una función de control social, pues transmite e irradia el compromiso de sus integrantes con la vigencia de normas justas, con la observancia de preceptos que involucran asumir responsabilidades de interés colectivo y con la adscripción a códigos morales que promueven la virtud. En quinto lugar, cumple una función de afirmación de la persona por sí misma, ofreciendo a sus integrantes el respeto, el resguardo y la promoción de su valor como persona, al margen de consideraciones de edad, sexo, capacidad económica e influencia de su integridad moral.

\footnotetext{
${ }^{16}$ Cfr. Trimbos, Convivencia, cit. nota n. 3, p. 206; BrICKLIN, Barry; BrICKLIN, Patricia, Padres liberales, hijos liberados, Traducción de Angulo, P., Pax, México 1982, p. 19; Dízz-Picazo; Gullón, Sistema, cit. nota n. 7, p. 34; MARTinez de AguirRe, Carlos, Diagnóstico sobre el Derecho de familia, Rialp, Madrid 1996, p. 17. Entre los autores señalados, Trimbos expresa que "mientras se conserve la función básica de la familia, es decir la función afectiva, los cimientos de la institución familiar permanecerán inconmovibles" (Trimbos, Convivencia, cit. nota n. 3, p. 210).

${ }^{17}$ Al respecto, vide la posición concordada por la Iglesia Católica Latinoamericana, expresada en el Documento de Puebla, al reflexionar sobre las funciones familiares, considera que además de la función procreadora, la familia tiene una proyección socializadora y estabilizadora, educativa, religiosa, de distracción y solaz, muy relacionada con la posición social y la preparación de los niños para asumir puestos significativos en la sociedad. En la misma perspectiva social, cumple una función económica, productiva y de consumo, que alude a la histórica consideración de la familia como una unidad de producción, en la cual se utiliza la fuerza de trabajo de todos los componentes en una empresa o tarea productiva en beneficio de todo el grupo, del jefe o de un extraño, actualmente afectadas por la incorporación de la mujer al mundo del trabajo y el cambio de roles en la relación familiar. Finalmente, constata una función política, en que en cada familia influyen de manera diferente factores ligados al cambio social, a saber, factores sociológicos (injusticia social, principalmente); culturales (calidad de vida); políticas (dominación y manipulación); económicas (salarios, desempleo, pluriempleo); religiosos (influencia secularista), entre muchos otros (Tercera Conferencia General del Episcopado LatinOamericano, La evangelización en el presente y en el futuro de América Latina. Documento de Puebla, CECH, Santiago de Chile 1979, p. 199).
} 
Por tanto y con un carácter comprensivo de lo ya dicho, la familia tiene una razón de funcionalidad social, por cuanto constituye en definitiva el factor que hace que la sociedad funcione ${ }^{18}$.

Si nos hacemos cargo de la recurrente afirmación de la existencia de una eventual o actual crisis de la familia, una opción válida para enfrentarla es vincular esta situación crítica con la pérdida o declinación de las funciones tradicionalmente reconocidas y valoradas en la familia, o más correctamente, a una transformación de las funciones atribuidas, ya que la noción de pérdida sólo alude a una parte del cambio de funciones, y en caso alguno puede identificarse con las funciones básicas que generalmente le son reconocidas, como la procreación y la sustentación de la especie, las que sigue cumpliendo cabalmente, pese a los cambios económicos y culturales que la afectan periódicamente. Probablemente, es más acertado advertir un cambio en la valoración de la función familiar por parte del Estado, en que, dependiendo de la visión colectiva imperante, puede dar cuenta de una mayor apreciación de su relevancia pública o, por el contrario, de su reducción cualitativa, al circunscribirla al ámbito privado, marginándose el Estado de interferir en su promoción, ya sea por desprecio de su importancia social, económica o política o derechamente por la preeminencia de un cambio ideológico, probablemente de cariz individualista liberal, extendido a la valoración decreciente de la familia ${ }^{19}$.

\section{EVOLUCIÓN DE LAS CONCEPCIONES SOCIALES PREDOMINANTES SOBRE LA FAMILIA}

Como sea que se valore el cambio suscitado en la apreciación pública de la familia, tras el diseño de las políticas públicas aplicadas en las últimas dos décadas y que jurídicamente se manifiesta en el Derecho de familia, se debe reconocer una evolución desde una concepción predominantemente social y marcadamente institucional sobre la familia, hacia una mirada preponderantemente enfocada en el sujeto individual que la constituye y sus circunstancias afectivas. Esta evolución ha dejado atrás una imagen institucionalizada de la familia, erigida sobre la base del matrimonio, ordenada jerárquicamente y di-

\footnotetext{
${ }^{18}$ Cfr. Hernández-Sampelayo; Crespo, ¿Familia o familias?, cit. nota 15, pp. 23 y ss., en relación con Pérez, Repensar, cit. nota n. 5, pp. 75 y 76. Sobre la función mediadora de la familia, entre individuo y sociedad, entre naturaleza y cultura y entre esfera privada y esfera pública, vide DonATI, Manual, cit. nota n. 9 , pp. 38 y ss.

${ }^{19}$ Cfr. SerRano, Sofía, "Cultura y familia: visión desde la historia", en Aylwin y Otros, La Familia, cit. nota n. 7, p. 16. Afirma la autora que la familia contemporánea está sometida a más demandas de lo que estuvo nunca en el pasado, pues asume sus antiguas funciones de procreación y sustentación de la especie, juega un papel económico fundamental y, además, proporciona el espacio del amor, del afecto y de la gratuidad de los esposos y de sus hijos. Esta constatación le permite concluir que nunca como ahora, fue el único y el último espacio del sentido de pertenencia del ser humano, porque en cierto sentido, la modernidad le ha relegado a ella resolver las carencias y absorber las múltiples contradicciones que ha generado la gran hazaña de la conquista de la libertad individual.
} 
rigida a la consecución de fines propios de la comunidad familiar, siendo éstos valorados y priorizados socialmente, sustituyéndola por una concepción de base contractual, cuya tipología no es necesariamente matrimonial, que tiende a la igualdad de sus integrantes y que sitúa muchas veces en un lugar secundario los intereses familiares comunitarios, los que son sustituidos cuando no alentados por la estructura socia ${ }^{20}$. Cabe destacar, sin embargo, que la transición entre el modelo jerárquico y el modelo asociativo de familia, no implicó necesariamente la sustitución inmediata de uno por otro, sino que mantuvieron ambos modelos expresiones coincidentes en un mismo período ${ }^{21}$.

La concepción de familia, sin referirnos críticamente a su expresión contemporánea, ha tenido una evolución social evidente en el último siglo, al igual que su recepción jurídica, amoldada siempre con retraso a la realidad que ha pretendido intervenir.

El modelo tradicional estaba basado en el predominio de la valoración institucional y económica de la familia. En esta concepción, la familia era considerada un verdadero centro económico, en el cual se distribuían las tareas necesarias para la subsistencia y desarrollo de la comunidad familiar extendida,

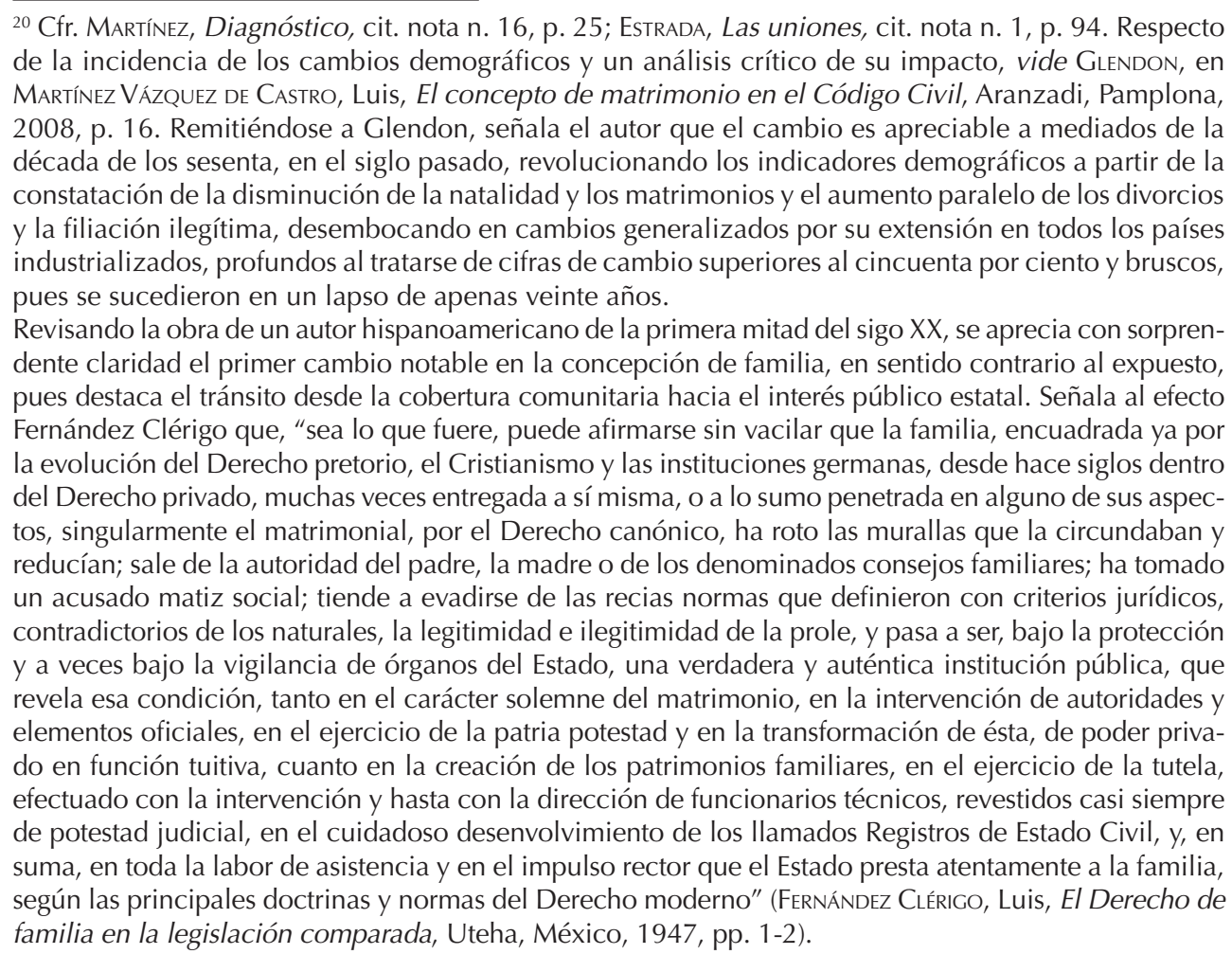

${ }^{21}$ Cfr. Diez-Pıcazo, Familia, cit. nota n. 6, pp. 22-24 
carácter que perdería progresivamente, de la mano de la externalización de las distintas funciones que antaño eran satisfechas en forma autárquica, como la educación y el trabajo.

Estos imperativos se vieron reflejados en una clara relación jerárquica entre sus integrantes, configurando un orden familiar traducido en un modelo jurídico considerado durante siglos como natural, aceptado y compartido por la costumbre, y cuya figura central era la potestad marital, a la cual estaban sujetos la esposa y los hijos ${ }^{22}$. Este modelo, de carácter marcadamente patriarcal y autoritario, con un fuerte sello rural, era tutelado por el legislador en aras de garantizar la estabilidad de la convivencia familiar e indirectamente, la propia estructura social, adoptando para conseguir tal objetivo reglas rígidas en materia de matrimonio (indisolubilidad), desigualdad de los cónyuges (potestad conyugal) y filiación (discriminación de la filiación extramatrimonial) ${ }^{23}$.

Esta forma de ordenación social, con un claro perfilamiento de los roles parentales, identifica la familia chilena de la segunda mitad del siglo XIX y la primera del siglo XX, proyectando secuelas culturales en la sociedad rural hasta finales de la centuria. Es esta realidad, aplicando el criterio histórico de situación normativa, la que rige tanto el Código Civil de Bello, como la Ley de matrimonio civil de 1884, cumpliendo sin duda con una necesidad de pertinencia jurídica y acendrado realismo legislativo, pero que, excedida en su tiempo, determinó su obsolescencia ante las nuevas realidades familiares, otorgando un fundamento sólido a la idea de reforma.

En esta ordenación social, vigente hasta principios de la segunda mitad del siglo XX en Chile, el padre constituye la presencia familiar en el mundo externo, siendo quien lo conoce, obtiene en él los recursos para sus subsistencia y protege a la comunidad familiar de sus amenazas, en tanto que la madre restringe su ámbito de acción a la esfera de la intimidad del hogar. Tanto el padre como la madre ejercen autoridad sobre sus hijos, caracterizándose aquél por su severidad normativa y la madre por el trato afectivo y comprensivo. En la sociedad semirural de la época, caracterizada además por la precariedad económica, la subsistencia familiar exigía la mayor eficiencia de los roles, estructurándolos rígidamente en el ámbito público respecto del padre y en el hogar respecto de la madre.

Desde un punto de vista jurídico, la regulación de las relaciones familiares no atribuía relevancia determinante a los afectos, toda vez que el modelo en aplicación se erigía sobre la necesidad de tutelar el interés predominante de la familia como institución y no el de los sujetos individuales. En la búsqueda de

${ }^{22}$ Cfr. SESTA, Michelle, Derecho de familia italiano. ¿Hacia nuevas transformaciones?, Universidad Externado de Colombia, Bogotá 2003, pp. 9-10.

${ }^{23}$ Cfr. SESTA, Derecho, cit. nota n. 22, pp. 9-10. 
tal propósito, adquiría sentido y relevancia el matrimonio con el carácter de indisoluble, indisponible por los cónyuges, al ser considerado como una realidad institucional que trascendía la voluntad e intereses de los individuos ${ }^{24}$.

Este modelo fue sustituido progresivamente, a la par del proceso de industrialización tardío que caracterizó la realidad socioeconómica chilena a contar de 1930, dando lugar al modelo de familia moderno-industrial, de carácter urbano, centrado en la asignación del rol de proveedor económico reconocido al varón y en la función de administradora del hogar, reconocida a la mujer. El evidente anacronismo y el desfase social e histórico del modelo tradicional, sin embargo, no fueron obstáculo para su vigencia más allá de lo económicamente compatible y políticamente prudente, conviviendo con una realidad social, económica y cultural distinta, lo que sólo es posible explicar recurriendo al soporte jurídico que le brindó el Estado.

Sin embargo, a contar de la década iniciada en 1960, se iniciará un nuevo período de grandes cambios económicos, sociales y culturales, que marcarán un hito referencial en el proceso evolutivo de la familia ${ }^{25}$.

En tal sentido, cabe destacar la incidencia de los procesos de reforma agraria en el medio rural y la reforma educacional en las ciudades, hechos que coinciden con una mejora económica ostensible, basada en el proceso de industrialización luego de la intervención estatal en la economía que introducirá el

\footnotetext{
${ }^{24}$ Cfr. Sesta, Derecho, cit. nota n. 22, y Garrido de Palma, Víctor, "Capitulaciones matrimoniales y regímenes económicos matrimoniales", en Delgado de Miguel, Juan Francisco, Instituciones de Derecho privado, t. IV, vol. I, Familia, Civitas, Madrid, 2001, p. 303. Asimismo, considérese González, La familia, cit. nota n. 7, pp. 20-32, y SESTA, Derecho, cit. nota n. 22, p. 10. Para un análisis de la caída del patriarcado, en la concepción de la autora, vide CASTILLA CORTÁzAR, Blanca, La complementariedad varón mujer. Nuevas hipótesis, $2^{\text {a }}$ Edición, Rialp, Madrid, 1996, p. 34.

${ }^{25}$ En términos comparados, el proceso que afectó a la sociedad española guarda notables similitudes con los acontecimientos que afectaron en general a muchos países de Latinoamérica y del sur de Europa, en particular, la brevedad temporal y la radicalidad del proceso experimentado de transformación social y cultural. Sin embargo, a diferencia de los países del centro y del norte europeo e, incluso, de la Europa meridional, España vivió intensos procesos de cambio social en unas pocas décadas. Desde el fin de la guerra civil hasta 1991, momento coetáneo con su asimilación europea, España se transforma en una sociedad urbano industrial y de servicios, dejando atrás de un modo radical e irreversible su especificidad rural y agraria, siendo acompañado este proceso por cambios demográficos, tales como importantes migraciones entre comunidades regionales, y desde pequeñas comunidades rurales hacia las grandes ciudades, caracterizándose además este proceso, por relevantes cambios socioculturales, como la generalización de la enseñanza, la incorporación de la mujer al trabajo asalariado, la difusión de la anticoncepción y la transformación liberalizadora de las conductas y costumbres sexuales. Todo ello, dentro de un marco político de asentamiento de las instituciones democráticas, de secularización de importantes sectores de la población y de consolidación de un sistema económico de base capitalista con componentes del estado de bienestar. Cfr. Montoro Gurich y Otros, Familia y cambio social en la España del Siglo XX, Rialp, Madrid, 2006, p. 17; GARrIDO, "Capitulaciones", cit. nota n. 24 p. 303, y BRIONeS MARTínez, Irene, "El diseño familiar: un análisis de Derecho comparado y de políticas familiares", en Pérez, Adán; Andrés Gallego, Juan, Palabra, Madrid 2001, p. 135. Para profundizar en las causas de las crisis de la familia, vide CASTÁN, Derecho, cit. nota n. 7, p. 53.
} 
régimen económico sustitutivo de importaciones, con una marcada pretensión antártica. Con la industrialización y la urbanización, se reducen drásticamente las empresas familiares y aumentan las personas que dependen de un salario, a la vez que mejoran los niveles educativos, especialmente de las mujeres. Los avances médicos determinan un aumento de la esperanza de vida, mayores grados de supervivencia y la incorporación de la regulación de la natalidad, facilitada por la amplia difusión de los métodos anticonceptivos ${ }^{26}$.

El desarrollo de los medios masivos de comunicación amplía el mundo de las influencias individualistas y hedonistas, especialmente de aquellas provenientes de Estados Unidos y Europa, teniendo un efecto colateral en la transformación fuertemente liberalizadora de las conductas privadas, propagándose rápidamente en un medio social propicio, pero cuyo traslado sin filtro cultural alguno, terminó por impactar negativamente en sociedades cuya economía y nivel comparativo de desarrollo determinaba racionalmente otras prioridades en la atención pública ${ }^{27}$.

Finalmente, avanzada la década de los setenta, el desmantelamiento del Estado de bienestar primero y la crisis económica luego, producen en Chile un impacto insoslayable en la vida familiar, expresada en el debilitamiento del rol del padre proveedor y jefe de familia, un aumento de la cesantía de los jóvenes, el aumento del trabajo femenino y, consecuencialmente, de los conflictos conyugales derivados de la modificación de los roles tradicionales en la pareja y al interior de la familia, agravados por el carácter forzado que los motivó ${ }^{28}$.

Resueltos los problemas de sobrevivencia, como ocurre con la sociedad chilena a contar de 1990, sus demandas se desplazan hacia la satisfacción de necesidades más complejas, que dan cuenta de anhelos más sofisticados, como una vida afectiva de pareja plena y simétrica, sin cabida para los sistemas de dominio varonil de antaño ${ }^{29}$.

Las condiciones reseñadas, exigieron una difícil adaptación de la institución familiar a las nuevas realidades, en especial, la vigencia de un modelo de economía insuficientemente regulada en función del bien común, y de la irrupción

${ }^{26}$ Considérese, al respecto, las obras colectivas de Aytwin Orarzún, Mariana, y Otros, La familia en Chile, aspiraciones, realidades y desafíos, CERC- ICHEH, Santiago de Chile, 1992, pp. 37-71 y deVALDÉs, Ximena, y Otros, Familia y vida privada ¿Transformaciones, tensiones, resistencias o nuevos sentidos?, FLACSO, Santiago de Chile, 2005. En perspectiva de análisis cristiano, vide Conferencia EPISCOPAL LATInOAmericana (CELAM), Fe Cristiana y Compromiso Social, CIDE, Santiago de Chile 1983.

${ }^{27}$ Considérese Giddens, Anthony, "Vivir en una sociedad postradicional", en UвECK y Otros, Modernización reflexiva: política, tradición y estética en el orden social moderno, Alianza, Madrid 1996, pp. 122-136. Asimismo, Valdés y Otros, Familia, cit. nota n. 26, y CELAM, Fe Cristiana, cit. nota 26.

${ }^{28}$ Cfr. ReYES, Carmen, "La Familia chilena hoy. Fundamentos para políticas públicas orientadas al grupo familiar", en AyıwIN y Otros, La familia, cit. nota n. 7, p. 43.

${ }^{29}$ ReYES, Carmen, "La Familia chilena hoy. Fundamentos para políticas públicas orientadas al grupo familiar", en AyLwIN y Otros, La familia, cit. nota n. 7, p. 43. 
de la cultura liberal, debiendo, además, hacer frente a los cuestionamientos sobre su consideración como mecanismo privilegiado de reproducción social de costumbres petrificadas, correspondientes a una concepción social autoritaria, religiosa y patriarcal, en evidente crisis.

En sintonía con la crítica anterior, los vínculos de sujeción fueron sustituidos por la libre elección, en una transformación que fue recogida por el Derecho civil en diversas reformas legales que se sucedieron progresivamente en las últimas décadas del siglo XX, mediante la introducción del divorcio, las normas de igualdad entre los cónyuges y la reforma que consagró la paridad jurídica entre hijos legítimos y naturales ${ }^{30}$, trayendo consigo el cambio del modelo de familia moderno-industrial por el modelo relaciona ${ }^{\beta 1}$.

Jurídicamente, se produce la crisis del modelo familiar institucional y el auge del paradigma de la autonomía de la voluntad, aplicada a las relaciones familiares regidas por el Derecho, con lo cual, siguiendo a Sesta, "al equilibrar las razones del grupo con el derecho de los individuos, [el sistema] termina esencialmente por acoger una visión fundamentalmente privada de las relaciones familiares, y en especial de la relación conyugal"32.

En un contexto explicado por esta transformación, la familia es reconocida como poseedora de un poder social notable para crear tejido social, a partir de la aplicación valorada de la biografía personal de sus integrantes, pero que debido a las coincidencias producidas en el seno familiar y exteriorizadas por su propia red, permiten a la familia constituirse también en un poderoso agente de cambio social, que puede contribuir de un modo efectivo a la existencia de personas equilibradas en la sociedad ${ }^{33}$.

El modelo de familia matrimonial, vale decir, la unión matrimonial estable y duradera de un hombre y una mujer con el proyecto común de tener y educar a los hijos, idealizado como el único socialmente aceptable, ha sufrido un proceso de fuerte debilitamiento en los últimos años ${ }^{34}$. En la

\footnotetext{
${ }^{30}$ Cfr. SESTA, Derecho, cit. nota n. 22, p. 11.

${ }^{31}$ Desarrollado por Francois de Singly, corresponde al modelo de familia contemporánea en que priman la lógica de los sentimientos y afectos por sobre el contenido eminentemente prescriptivo de las normas, en particular las morales y jurídicas. Cfr. VALDÉs y Otros, "Entre la reinvención y la tradición selectiva: familia, conyugalidad, parentalidad y sujeto en Santiago de Chile", en VALDÉs; VAldés (Edts.), Familia y vida privada. ¿Transformaciones, tensiones, resistencias o nuevos sentidos?, FLACSO, Santiago de Chile, 2005, p. 165.

32 Vide SeSTA, Derecho, cit. nota n. 22, p. 12.

${ }^{33}$ Cfr. Montoro y Otros, Familia, cit. nota n. 25, p.16. Asimismo, considérese Garkido de Palma, "Capitulaciones matrimoniales y régimen económico matrimonial", en DelGADO, Instituciones, cit. nota n. 24 , pp. 203 y ss.

${ }^{34}$ Cfr. Garkido de Palma, "Capitulaciones matrimoniales y régimen económico matrimonial", en DelGADO, Instituciones, cit. nota n. 24, pp. 203 y ss.
} 
actualidad, el matrimonio tiende a ser apreciado mayoritariamente como una entidad que explica y reconoce su origen en la asociación voluntaria de un hombre y de una mujer, en donde el amor ocupa un lugar central y determinante en la motivación de la unión y que también provee la fortaleza para la subsistencia del vínculo formal conyugal, identificado a su vez con el matrimonio.

La tendencia predominante acepta la posibilidad de existencia de amor sin matrimonio, pero no del matrimonio sin amor. Esto ha llevado a que sea habitual y normal hablar de una relación de pareja, expresión inusual en una sociedad tradicionalmente acogida a las pautas legitimadas por la religión mayoritaria y por leyes, cuyo fundamento moral era también cercano a la visión religiosa de la mayoría. El sexo adquiere un sentido en sí mismo, tanto dentro del matrimonio como fuera de él, adquiriendo una nueva legitimidad, que no aparece ligada solamente a la procreación. La maternidad, impactada por los métodos de contracepción, se hace también voluntaria, a la vez que incide en la disminución del número de hijos. La familia extendida desaparece ante el predominio de una familia nuclear, cada vez más aislada socialmente y orientada hacia la educación de los hijos ${ }^{35}$.

Sobre esta realidad, parte de la doctrina estima que ya comienza el ocaso del concepto tradicional de familia, que había privilegiado la consideración de la familia fundada en el matrimonio, asumiéndola como una experiencia paradigmática del amor humano e irradiador de un efecto altamente civilizado. Por el contrario, el paradigma que se asienta y consolida abrumadoramente, sustentado en una realidad que tiende a ser dominante, se caracteriza por la promoción de una pluralidad de normativas que se postulan todas ellas como socialmente legítimas ${ }^{36}$.

En línea con esta tendencia, es también recurrente hablar de "familias" y no de familia, pretendiendo con ello sus impulsores ampliar el espectro a otras realidades, igualmente válidas desde un punto de vista del reconocimiento social y de la necesidad de su tutela jurídica. Se incluye en este ensanche del concepto, expresiones heterogéneas que van desde la familia extendida tradicional, hasta las uniones de personas del mismo sexo, pasando entre estos dos extremos por las convivencias heterosexuales no reguladas civilmente y las manifestaciones de convivencia propias de sectas religiosas destructivas, algunas de las cuales se autodenominan familias ${ }^{37}$.

${ }^{35}$ Cfr. SerRano, "Cultura y familia: visión desde la historia", en Aylwin y Otros, La Familia, cit. nota n. 7, p. 15.

${ }^{36}$ Cfr. VILADRICH, La familia, cit. nota n. 6, p. 33.

37 Vide Corbal Fernández, "La doctrina jurisprudencial actual en el Derecho de familia", en Navarro, El nuevo, cit. nota n. 3, p. 209. 
En este sentido, cabe distinguir diferentes propósitos, que deben también ser valorados de un modo diferente. Así, la necesidad de incluir en la denominación familia, además de la familia nuclear basada en el matrimonio, tanto la familia extendida como las familias nucleares y extendidas no basadas en la formalización de la unión de los padres, que originan el nexo familiar, aparece sin duda evidente ${ }^{38}$. En este sentido, no debiera ser cuestionada esta interpretación jurídica, con base en razones religiosas o morales, toda vez que su recepción en el Derecho chileno -aceptando esta mirada- no deja lugar al realizar una lectura desde el marco constitucional.

Sin embargo, estimamos que las manifestaciones familiares reales, tanto en su expresión nuclear como extendida, formalizada o no, que dan cuenta de lazos de filiación, alianza y afecto, constituidos o que tienen su origen en una unión heterosexual fructífera, remiten sin duda a la noción de familia, no requiriéndose el uso de la alternativa terminológica de "familias", ampliación conceptual que no se justifica en el afán de reconocimiento de una pluralidad de realidades, sino en su funcionalidad con el propósito de eliminar alguno de los elementos esenciales de la familia, como la filiación. Esto, para introducir como elementos de una definición legal, otras características que no tienen que ver directamente con ella, como la alianza con una motivación religiosa entre adultos o las convivencias temporales entre personas del mismo sexo, que procuran alcanzar un estatuto mejorado de su aceptación social.

Esta última perspectiva, en particular, deriva la cuestión a la consideración de un cambio en el núcleo definitorio de la naturaleza familiar, trasladando la atención pública y especialmente la eventualidad de una tutela jurídica privilegiada a las distintas relaciones que establece uno de los individuos de la pareja, antes que a la relación principal, que tiene por sentido y justificación la formación del hogar destinado a la crianza de los hijos. Esta opción, que basa el sujeto familiar en los deseos, conduce finalmente a la legitimación social de la familia alternativa, entendida como arreglo de conveniencia y, en definitiva, al asentamiento público de la noción ideológica del multifamilismo ${ }^{39}$.

\footnotetext{
${ }^{38}$ Figueroa Yáñez resalta como un suceso común de nuestra época, que una pareja, casada o no, que tenga hijos, se disuelva ya sea por divorcio o simple término de la convivencia, determinando que sus componentes rehagan sus respectivas vidas con otras personas de su misma condición, con las que más tarde tengan una descendencia, calificándolas como familias ensambladas, las que son definidas por Kemelmajer, como "las que se originan en una nueva unión tras la separación, divorcio o viudez, cuando uno o ambos cónyuges tienen hijos de un vínculo anterior" (FigueroA Yá̃̃ez, Gonzalo, "El pacto de convivencia: una alternativa al pacto de matrimonio", en Varas Braun, Juan Andrés; Turner Saelzer, Susan (Edits.), Estudios de Derecho civil, LexisNexis, Santiago de Chile, 2005, pp. 432-433).

${ }^{39}$ La familia alternativa es una noción surgida al amparo del multifamilismo, concepto promovido en su acepción social y política por la corriente de pensamiento conocida como "Tercera vía", basada en la obra de Giddens. Las familias alternativas, entendidas como arreglos de convivencia, carecen de algunas notas de funcionalidad, como la equidad generacional, en tanto no contemplan las relaciones
} 
EVOLUCIÓN Y ACTUALIDAD DE LA CONCEPCIÓN DE FAMILIA. UNA APRECIACIÓN DE LA INCIDENCIA POSITIVA DE LAS tendencias dominantes a partiR de la Reforma del Derecho Matrimonial ChILeNO

En consonancia con las afirmaciones precedentes, surge con cierta reiteración la inquietud sobre la actual valorización social de la familia institucional, lo que se traduce en perspectivas diferentes sobre la realidad apreciable, puesto que para unos se ha producido una desinstitucionalización de la familia, y para otros, una necesaria superación de un criterio restringido y descentrado de su naturaleza.

Al respecto, cabe precisar que la familia es ciertamente un hecho social, que el Derecho reconoce para su protección, pero que el discurso sociopolítico dominante en la actualidad, desecha como núcleo de asignación, construcción o reserva de poder económico o político, con proyección cultural. En la realidad hispanoamericana, por su parte, tiene fuerza de sustentación el concepto de integración de la realidad familiar existente, en la noción jurídica cuya protección prodiga vía su consideración institucional ${ }^{40}$.

En una vertiente diferente, el intento de solventar las diferencias de concepción de la familia, explorando la noción de pluralidad de sus expresiones ${ }^{41}$, no parece aceptable, por cuanto elude la noción de familia, naturalmente configurada, que naciendo de ciertas bases comunes e ideales, se ve afectada por los cambios vitales de sus integrantes, y que por su importancia social, requiere del Estado su aseguramiento y protección. Para ello acude al expediente de su formalización, que deriva en institucionalización, no para constituir artificialmente un marco que, derivado en camisa de fuerza, ceda a la tentación de incluir dentro de él, sólo lo que es coincidente con las propias valoraciones y excluya lo que se estima ajeno. Tampoco, para eludir el esfuerzo del consenso

de cuidados equitativos que supone la transmisión de la vida y que se manifiestan en el cuidado de niños y ancianos. Cfr. Pérez, Repensar, cit. nota n. 5, p. 81. Diversos autores coinciden en la tesis de que ceder a la noción pluralista de familias, en el sentido aludido en el texto, importa una renuncia a la idea de familia, pues implica la consideración y aceptación de todas las entidades que se auto atribuyan esta calidad. Así, Pérez Adán destaca que, en España, "ese resurgimiento [aludiendo a la familia nuclear], también se producirá una vez pasada la moda que ampara el afán moldealista de la realidad, que abraza la ideología del multifamilismo, por lo que se refiere al "diseño" de pautas familiares. Los hechos vitales al final terminan por afirmarse y el hecho familiar funcional también lo hará con legislación ad hoc" (Pérez, Repensar, cit. nota n. 5, p. 77). También Hernández; CresPo, ¿ Familia...? cit. nota n. 15, pp. 19-20). En contra se pronuncian Díez-Picazo y Gullón Ballesteros, quienes afirman la inexistencia de un concepto intemporal de familia, proponiendo que, más exacto que hablar de familia en singular, como institución universal y única, es hablar de "familias" en plural, para designar modelos con arreglo a los cuales los grupos humanos se han organizado históricamente (Diez-PICAzo; Gullón, Sistema, cit. nota n. 7, p. 32).

${ }^{40}$ No sólo se colige la afirmación desde un criterio meramente civil, que trasunta aparente neutralidad, sino también en la propia y comprometida pastoral católica. Así, vide ConferenCia General Del EPISCOPADO LatinOAmericANo, La evangelización en el presente y en el futuro de América Latina. Documento de Puebla, Conferencia Episcopal de Chile, Santiago de Chile 1979, p. 199. Respecto de los cambios operados en España y su recepción jurídica, vide LACRUz Berdejo (Coord.), Matrimonio y divorcio. Comentarios al Título IV del Libro Primero del Código Civil, 2ª Edición, Civitas, Madrid, 1994, p. 691.

${ }^{41}$ Díez-Picazo; Gullón, Sistema, cit. nota n. 7, p. 72. 
social en un mínimo común denominador, optando en cambio por renunciar a la idea de familia, propugnando la consideración de todas las entidades que se autoatribuyan esta calidad.

Sin perjuicio de lo anterior, el debate sobre la valoración social dominante y la recepción jurídica de dicha apreciación, en torno a las agrupaciones formadas por adultos, está abierto y no tiene visos de concluir. Asumiendo dicha apertura, una de las cuestiones aún no resueltas, tiene por objeto la asociación de individuos que, motivados por el mutuo afecto, forman una pareja que en sus valores y actos concordantes, manifiestan una coincidencia con la visión social mayoritaria en la prioridad asignada a la solución de ciertos problemas públicos acuciantes, como ocurre con la custodia de los menores en situación de abandono. Si la duda surge por la decisión de institucionalizar la tutela de los menores ante la imposibilidad, en un caso específico, de encontrar una pareja heterosexual que se haga responsable de la custodia y crianza, la disyuntiva es discutible en una perspectiva ética de base ciudadana, toda vez que a diferencia de las uniones temporales con finalidades estrictamente de conveniencia individual, es indudable que, superada la objeción religiosa o cultural contraria a este tipo de uniones, ellas pueden cumplir exitosamente una función social necesaria y por tanto valorada.

\section{UNA APROXIMACIÓN A LA FAMILIA NUCLEAR CONTEMPORÁNEA Y SUS CARACTERÍSTICAS}

La pérdida de funciones tradicionales atribuidas a la familia, en gran medida, provocada por los cambios económicos y socioculturales de las últimas décadas, según lo visto precedentemente, ha terminado por extinguir progresivamente la extensión familiar, determinando el tránsito sociológico desde la familia extensa a la familia nuclear.

La familia nuclear, que es la expresión preponderante en la actualidad, reconoce, sin embargo, ciertas características que admiten una consideración crítica, por el impacto social que sus efectos han tenido, en particular los referidos al incremento de la autosuficiencia y aislamiento de las parejas conyugales, los cuales se atribuyen en gran medida al renovado apogeo en el campo del Derecho de familia, del principio de la autonomía de la voluntad individual y del paradigma igualitario ${ }^{42}$.

En lo que respecta a la autosuficiencia y aislamiento de las parejas conyugales, cabe destacar que iniciada una convivencia, formalizada o no, los esposos, cónyuges o convivientes establecen una residencia independiente o procuran establecerla, siendo la calidad de allegado al núcleo previo, tanto por

${ }^{42}$ Cfr. P. Moreno, "Cultura y familia: visión desde la antropología", en Aytwin y Otros, La Familia, cit. nota n. 7, p. 24; Burgess; Locke, citados en Trimbos, Convivencia, cit. nota n. 3, p. 95. 
estrechez económica o por opción, una suerte de patología social, que debe ser observada como excepción en el proceso de independencia respecto a los padres después del matrimonio. Con ello, se revierte la tendencia a la familia extensa, que históricamente ha servido de soporte, tanto por la disponibilidad tácita de ayuda externa a los problemas de la pareja, como de ésta a su comunidad familiar de referencia.

La tendencia genera efectos en tres planos. En primer lugar, circunscribe los éxitos y desventuras de la familia nuclear al núcleo básico, sitio en donde se deben adoptar las decisiones vitales, procurar el equilibrio emocional de la pareja y afrontar las consecuencias. En segundo lugar, rompe la cadena de solidaridad generacional, impidiendo la recurrencia natural a los parientes en caso de dificultad extrema y, en la eventualidad de un momento crítico de la vida conyugal, incide en la radicalidad de la decisión que soluciona el problema. En tercer lugar, genera demandas de asistencia social (Estado) y comunitarias (familia extendida), que inciden directamente en la demanda de políticas públicas, las que por provenir de un agente externo, exigen las más de las veces una intromisión de los valores y prioridades de los grupos dominantes y no de aquellos correspondientes a la comunidad de referencia. Jurídicamente, legitima la intervención institucional en las situaciones críticas, promueve el surgimiento de una normativa paliativa de los efectos sociales negativos y fomenta una verdadera explosión de Derecho social, el que se concibe no como un instrumento subsidiario de la capacidad de resolución de conflictos, radicada naturalmente en el seno de la comunidad familiar, sino directamente radicada en su periferia inmediata. Esto lleva al predominio de una concepción de sociedad de individuos por sobre la concepción de sociedad de personas, que son tales en la noción de comunidad ${ }^{43}$.

En segundo lugar, en lo que respecta al predominio del principio de autonomía de la voluntad individual en la elección de la pareja, cabe consignar que un rasgo característico relevante, marcado a partir de la década de 1960 y plenamente asentado en la década de 1980, lo constituye la mayor preeminencia de la autonomía de la voluntad individual, a la hora de la elección de la pareja, relegando a un segundo plano otras consideraciones, como los intereses particulares de la familia de proveniencia, contribuyendo así a la pérdida de una realidad ética-social no basada en la voluntad, como afirmaba Castán Tobeñas ${ }^{44}$.

\footnotetext{
${ }^{43}$ Para un estudio de los principios éticos que trascienden el individualismo y fundamentan la concepción de sociedad de personas en la noción de comunidad, vide ConILL, "La conformación de deberes compartidos: una ética comunitaria frente al modelo individualista", en Pérez ADÁN, José, Las terceras vías, Eiunsa, Madrid, 2001, pp. 149 y ss.

${ }^{44}$ Cfr. CASTán, Derecho, cit. nota n. 7, p. 43.
} 
Esta revalorización de la voluntad individual se encuentra, a su vez, fuertemente motivada por la consideración de la afectividad, en su acepción psicológica de afecto vivo ${ }^{45}$, como factor determinante de la construcción de una relación interpersonal de carácter no patrimonial, traduciéndose con mayor precisión en la noción de afecto conyugal. Esta visión se expresa en la elección de una pareja, en tanto y sólo si se aprecia la existencia de afectos, idealmente recíprocos, entre ambos contrayentes, que califican subjetivamente su relevancia y suficiencia para fundar sobre ellos el compromiso matrimonial. Este predominio de la afectividad amorosa, por sobre otros factores, como los intereses comunes o la mera camaradería, han derivado en que su sobrevaloración se constituya en condición esencial de la permanencia del compromiso vincular, de modo tal que su ausencia, decadencia o extinción determinan también la terminación de la voluntad asociativa ${ }^{46}$.

Sus efectos jurídicos, se aprecian en la revalorización del contractualismo y del principio consensual, en tanto posibilitan la recepción normativa de la preponderancia asignada al factor afectivo, como motivo legítimo que induce a la celebración del acto jurídico y a su extinción ${ }^{47}$. Ello se expresa, entre otros aspectos, en la consideración acuciosa de la concurrencia de impedimentos que impiden u obstaculizan el ius connubii, derecho éste que es elevado generalmente al rango constitucional y es objeto de consideración en acuerdos supraestatales.

Una visión crítica en torno a la primacía del afecto conyugal sostiene que habría contribuido a la desinstitucionalización de la familia, en tanto que la radicación en sede contractual, privada, habría conducido a una pérdida progresiva voluntaria de su ubicación en la esfera del orden público ${ }^{48}$. Al respecto, si bien se acepta habitualmente que el Derecho de familia se distingue del Derecho patrimonial por la indisponibilidad de las normas que le brindan el carácter institucional y restringen la calidad contractual al momento constituti-

\footnotetext{
${ }^{45}$ Cfr. Kuypers (Coord.), Breve Enciclopedia de Filosofía y Psicología, Traducción de García; Mercader, Carlos Lohlé, Buenos Aires, 1974, p. 22. La expresión significativa del afecto vivo es el amor matrimonial, que constituye a la vez una manera de ser y un sentimiento fundamental e irreductible del ser humano. No se refiere, por tanto, a la acepción jurídica ligada a la intención o voluntad de vincularse en sociedad.

${ }^{46} \mathrm{Al}$ respecto, considérese ARCOS VIEIRA, María Luisa, La desaparición de la affectio maritalis como causa de separación y divorcio, Aranzadi, Elcano, Navarra, 2000, pp. 41 y ss.

${ }^{47}$ En España, la modificación del CC por la Ley 30/ 1981 de 7 de julio, según Ferrer, vino a inscribirse dentro de las reformas del Derecho de familia que vienen sucediéndose durante las últimas décadas en el mundo occidental, basadas en una concepción individualista del matrimonio y la familia, que acentúa la contractualidad y la privatización del matrimonio, manifestaciones ambas de su secularización (Cfr. FerRer OrTiz, Javier, El matrimonio canónico en el ordenamiento español, Eunsa, Pamplona, 1986, pp. 68 y 69).

${ }^{48}$ Cfr. Martínez, Diagnóstico, cit. nota n. 16, pp. 30 y ss.
} 
vo, es posible, sin embargo, distinguir la vinculación jurídica paterno filial del vínculo jurídico conyugal civil, caso este último en que la motivación para su celebración, entendiendo que se trata del contrato matrimonial, mantiene las características exigibles en tanto negocio jurídico, a menos que se perfeccione en sede eclesiástica.

La ausencia inicial o desaparición de la affectio maritalis ${ }^{49}$, entendido en el sentido asignado en estas líneas, podría ser considerada un criterio válido en perspectiva civil, para la terminación del contrato devenido socialmente en institución. La cautela del derecho a la observancia de principios filosóficos o creencias religiosas, debe estar dada en la garantía constitucional respectiva, traducida legalmente en el derecho de opción entre sistemas reguladores, o al menos, entre formas de celebración que den cuenta del respeto jurídico al significado atribuido por los contrayentes al matrimonio, por cierto, dentro del marco civil vigente. Asimismo, suponiendo que el afecto conyugal fuera especialmente valorado por un sujeto, no debe considerarse necesariamente que la afectividad humana perjudique, minusvalore o torne inconveniente su consideración a propósito de la constitución y reconocimiento social de una familia o de la celebración de un matrimonio, incluso en perspectiva jurídica civil, ya que la afectividad no siempre debe ser rechazada como algo opuesto a la perfección de la persona, pues corresponde objetivamente a valores reales ${ }^{50}$.

Finalmente, cabe realizar una reflexión sobre el primado del principio de igualdad en las relaciones entre los sujetos constituyentes de la comunidad familiar. En efecto, una consecuencia de los cambios económicos y culturales ocurridos en la década de 1960, se aprecia como efecto del ingreso masivo de la mujer al mundo del trabajo, tradicionalmente reservado al varón, impactando activamente en la demanda de igualdad jurídica de la mujer. Traducida inicialmente en la modificación de los patrones ordenadores de los regímenes patrimoniales matrimoniales, esta tendencia derivó en la regulación de los derechos y deberes conyugales, para finalmente concluir en una concepción culturalmente revolucionaria de los ámbitos de lo masculino y lo femenino en su relación con el mundo externo e interno, que aseguró a ambos la presencia

\footnotetext{
${ }^{49}$ La expresión affectio maritalis admite distintas acepciones, siendo una de las más comunes, la que la refiere a convivencia matrimonial, de modo tal que la constatación de su inexistencia equivale a la separación de hecho de los cónyuges. Sin embargo, interesa aquí la acepción que la concibe como afecto conyugal, en el sentido de relación sentimental que une a la pareja, cuya desaparición o pérdida durante la ruptura matrimonial, se expresa en tirantez, desavenencias e incluso malos tratos entre los cónyuges. Cfr. ArCos, La desaparición, cit. nota n. 43, pp. 20 y 34-39.

${ }^{50}$ Cfr. Maló Pé, Antonio, Antropología de la afectividad, Eunsa, Pamplona, 2004, p. 170. Expresa también el autor que la afectividad humana aparece "marcada íntimamente por el carácter tendencial del hombre hacia lo que, desde algún aspecto, le resulta conveniente o contrario, pues se refiere a la inclinación del hombre hacia su fin".
} 
prioritaria en una u otra dimensión del desarrollo personal, por opción y con la posibilidad de adecuarlo periódicamente a las necesidades familiares y a la voluntad de los partícipes ${ }^{51}$.

Esto ha concluido en el término de la barrera de exclusividad de lo público para el varón y lo privado para la mujer, determinando no sólo su participación en el ámbito público, con sus rangos de poder público incluidos, sino además el requerimiento de trato igualitario por parte del varón, respecto de la crianza de la prole, así como del derecho de vivir y expresar la afectividad paterno filial, sin marcos culturales prefijados y restrictivos. Asimismo, ha contribuido a asentar progresivamente que las decisiones se adoptan mediante deliberación entre marido y mujer, en las que participan los hijos a medida que van haciéndose mayores.

Las consecuencias jurídicas de este cuadro, entre otras, han sido la modificación radical de los regímenes económicos matrimoniales en favor de la separación de bienes y en desmedro de la idea de comunidad, la modificación del Derecho del trabajo y, en materia civil no patrimonial, la igualdad de trato por parte del Estado en los asuntos atingentes a la filiación, lo que ha tenido por efecto jurídico la progresiva igualación del reconocimiento de los derechos de ambos progenitores por igual respecto de los hijos comunes y, en definitiva, la aceptación creciente de la demanda por custodia compartida, tanto durante el estado matrimonial como en la eventualidad de un momento crítico.

\section{SíNTESIS CONCLUSIVA}

1. Tanto la definición esencial como la justificación social de la familia, están basadas en la familia natural, la que es apreciada como el modo general mediante el cual la sociedad realiza funciones esenciales para su supervivencia $y$, en un estadio de evolución superior, ciertas funciones sociales que no pueden ser realizadas por instituciones distintas de ella. A partir de esta afirmación, puede postularse que la familia es el lugar en que se constituyen las relaciones fundamentales decisivas de la persona humana.

2. El modelo de familia matrimonial, entendido como la unión matrimonial estable y duradera de un hombre y una mujer con el proyecto común de tener y educar a los hijos, ha sufrido un proceso sostenido de debilitamiento en los últimos años, debiendo coexistir con expresiones de matriz ideológica, que tienden a mutar el carácter comunitario de la familia por uno eminentemente social y consensual. La familia no está ya ligada exclusivamente al matrimonio ni tampoco es actualmente el único modelo socialmente aceptable.

${ }^{51}$ Sobre la decadencia del concepto patriarcal, vide CASTILLA; CORTÁzAR, La complementariedad, cit. nota n. 24, p. 34. 
3. La decadencia o extinción del modelo patriarcal de familia, ha ido a la par del deterioro del modelo construido en torno al estado de bienestar. El nuevo paradigma dominante viene determinado por los efectos sociales y culturales del modelo liberal económico, cuyos efectos disgregadores de la familia han sido evidentes.

4. Se concluye en la necesidad de incluir en la denominación familia, tanto la familia nuclear basada en el matrimonio, como la familia extendida, así como también las familias nucleares y extendidas no basadas en la formalización de la unión de los padres, completas o incompletas, que originan el nexo familiar, sin que ello implique necesariamente comprender las expresiones ideológicas que propugnan el multifamilismo.

5. La respuesta más acertada frente a la afirmación de la existencia de una crisis de la familia, es vincular esta situación crítica con la transformación de las funciones atribuidas tradicionalmente a la familia, promovida o estimulada por su circunscripción al ámbito privado y la progresiva marginación de la interferencia del Estado, causada por el desprecio de su importancia social, económica o política o derechamente, por la preeminencia de un cambio ideológico de cariz individualista liberal, extendido a la familia.

6. El contexto generado por la transformación cultural y social del liberalismo, sin embargo, también ha determinado un reconocimiento de la familia como poseedora de un poder social que le permite contribuir a la creación del tejido social, basada en la potencialidad de la personalidad individual de sus integrantes, de sus propias coincidencias y de su capacidad de proyección al medio externo, constituyéndose en un también poderoso agente de cambio social.

7. El predominio de la familia nuclear ha tenido como rasgos distintivos el progresivo aislamiento del núcleo constituido por la pareja, en lo cual ha incidido tanto la revalorización del principio de autonomía de la voluntad individual, como la igualdad jurídica de los constituyentes de la relación y sujetos consorciales del estado matrimonial.

8. La revalorización de la autonomía individual, sin embargo, se ha visto tensionada por la contradicción expuesta por el requerimiento de la intervención social representada por el Estado en las situaciones críticas de la relación conyugal y de la vida familiar.

\section{BibLiOGRAFíA}

Aylwin Oyarzún, Mariana y Otros, La familia en Chile: Aspiraciones, realidades y desafíos, CERC/ICHEH, Santiago de Chile, 1992.

Arcos Vieira, María Luisa, La desaparición de la affectio maritalis como causa de separación y divorcio, Aranzadi, Elcano, Navarra, 2000. 
Buttiglione, Rocco, La persona y la familia, Traducción de Esquivias A., Palabra, Madrid 1999.

BrICKLIN, Barry; BrICKLIN, Patricia, Padres liberales, hijos liberados, Traducción de Angulo, P., Pax, México, 1982.

Castán Tobeñas, Derecho civil español, común y foral, $V$, Derecho de familia, vol. I, 12ª Edición, Reus, Madrid, 1994.

Castellán, Ivonne, La familia, Traducción Martínez, H., Fondo de Cultura Económica, México, 1995.

CASTILLA CoRTÁzAR, Blanca, La complementariedad varón mujer. Nuevas hipótesis, $2^{a}$ Edición, Rialp, Madrid, 1996.

Conferencia General Del Episcopado Latinoamericano, la evangelización en el presente y en el futuro de América Latina. Documento de Puebla, Conferencia Episcopal de Chile, Santiago de Chile, 1979.

1983. , Fe Cristiana y Compromiso Social, CIDE, Santiago de Chile

CoRnejo ChÁvez, Héctor, Derecho familiar peruano, $10^{a}$ Edición, Gaceta Jurídica, Lima, 1999.

Corral Talcianı, Hernán, Familia y Derecho, Universidad de los Andes, Santiago de Chile, 1994.

Del Picó Rubıo, Jorge, Derecho matrimonial chileno, Abeledo-Perrot, Santiago de Chile, 2010.

Delgado De Miguel, Juan Francisco, Instituciones de Derecho privado, t. IV, vol. I, Familia, Civitas, Madrid, 2001.

Dízz-PıCazo, Luis, Familia y Derecho, Civitas, Madrid 1984.

Díez-Picazo, luis; Gullón Ballesteros, Alberto, Sistema de Derecho civil, IV, Tecnos, Madrid, 2006.

Donatı, Pierpaolo, Manual de Sociología de la familia, Traducción de Herrera, M.; Pagés, S., Pamplona, 2003.

Estrada Alonso, Eduardo, Las uniones extramatrimoniales en el Derecho civil español, Civitas, Madrid, 1986.

Fernández Clérigo, Luis, El Derecho de familia en la legislación comparada, Uteha, México, 1947.

Ferrer Ortiz, Javier, El matrimonio canónico en el ordenamiento español, Eunsa, Pamplona, 1986.

FLECHA ANDRÉs, Juan, La transmisión de valores en la familia multicultural, Madrid, 2002.

González Porras, José Manuel, La familia, el derecho y la libertad, Monte de Piedad, Córdoba 1987, 
Hernández-Sampelayo, María; Crespo Garrido, Marcelo, ¿Familia o familias? Estructura familiar en la sociedad actual, Sekotia, Madrid, 2005.

KIPP, Theodor; Wolff, Martin, Derecho de Familia, I, Bosch, Barcelona, 1947.

KuYPers (Coord.), Breve Enciclopedia de Filosofía y Psicología, Traducción de García; Mercader, Carlos Lohlé, Buenos Aires, 1974.

Lacruz Berdejo (Coord.), Matrimonio y divorcio. Comentarios al Título IV del Libro Primero del Código Civil, 2ª Edición, Civitas, Madrid, 1994.

2002.

, Elementos de Derecho civil, IV, familia, Dykinson, Madrid,

LASARTE, Carlos, Derecho de familia, 4a Edición, Marcial Pons, Madrid 2005.

Maló Pé, Antonio, Antropología de la afectividad, Eunsa, Pamplona, 2004.

Maluquer de Motes, Carlos, Derecho de familia, Bosch, Barcelona, 2005.

Martínez de Aguirre, Carlos, Diagnóstico sobre el Derecho de familia, Rialp, Madrid 1996.

Martínez VázQuez de Castro, Luis, El concepto de matrimonio en el Código Civil, Aranzadi, Pamplona, 2008.

Mizrahl, Mauricio, Familia, matrimonio y divorcio, Astrea, Buenos Aires, 2001.

Montoro Gurich y Otro, Familia y cambio social en la España del Siglo XX, Rialp, Madrid, 2006.

Navarro Viñuales, José María (Dir.), El nuevo Derecho de familia: modificaciones legislativas y tendencias doctrinales, Thomson Civitas, Cizur Menor, Navarra, 2006.

Pérez Adán, José, Las terceras vías, Eiunsa, Madrid, 2001.

SESTA, Michelle, Derecho de familia italiano. ¿Hacia nuevas transformaciones?, Universidad Externado de Colombia, Bogotá, 2003.

Tercera Conferencia General del Episcopado Latinoamericano, La evangelización en el presente y en el futuro de América Latina. Documento de Puebla, $\mathrm{CECH}$, Santiago de Chile, 1979.

TrimBos, Carlos, Convivencia en el matrimonio y la familia, Carlos Lohlé, Buenos Aires, 1966.

UneCK y Otros, Modernización reflexiva: política, tradición y estética en el orden social moderno, Alianza Editorial, Madrid 1996.

VALDÉs, Ximena, y VALDÉs, Teresa (Ed.), Familia y vida privada. ¿Transformaciones, tensiones, resistencias y nuevos sentidos?, Flacso, Santiago de Chile 2005.

Varas Braun, Juan Andrés; Turner Saelzer, Susan (Edits.), Estudios de Derecho civil, LexisNexis, Santiago de Chile, 2005.

VILADRICH, Pedro Juan, La familia. Documento 40 ONG's, Rialp, Madrid 1994. 
